\title{
IMITAÇÃO, EMULAÇÃO, MODELOS E GLOSAS \\ o paradigma da mimesis na literatura dos séculos XVI, XVII e XVIII
}

Thiago Saltarelli*

Universidade Federal de Minas Gerais

\begin{abstract}
RESU MO
As poéticas dos séculos XVI, XVII e XVIII, ditas "clássicas" por retomarem elementos da Antiguidade greco-latina, pautam-se largamente pela noção de mímesis na elaboração de seus pressupostos e preceptivas. $\mathrm{O}$ artigo busca, portanto, investigar a evolução e amplificação do conceito de mímesis ao longo dos séculos e refletir sobre sua permanência naquelas poéticas, salientando suas novidades e especificidades, desenvolvidas pela literatura da época.
\end{abstract}

PALAVRAS - CHAVE

Mímesis, glosa, Literatura clássica

Desde as primeiras abordagens da mímesis entre os antigos gregos, esta se constituiu como um dos fundamentos da criação artística, sem que tal ideia fosse posta à prova pelo menos até o século XVIII. Inicialmente, ela esteve ligada a um contexto mítico, religioso, quando não se tratava ainda de potencializar uma imagem do real, mas de exprimir uma realidade oculta, relacionada diretamente com os deuses. A ideia de mimetizar significava ser possuído pelo deus, e assim, de certa forma, imitá-lo ou materializá-lo por meio de um estado de êxtase. Daí se depreende a estreita ligação da noção de mímesis com os cultos de Dioniso, deus dos excessos. Tal vínculo com os cultos dionisíacos estabeleceu uma relação direta entre a mímesis e a música, a dança e aquilo que hoje designamos de mímica, tomando a própria raiz da palavra grega. A partir dessa associação, o conceito de mímesis, incorporado ao universo das manifestações artísticas, ainda que rudimentares, vai ganhando cada vez mais destaque. Entra no âmbito da filosofia e em seguida no da poética, tornando-se, como dissemos acima, fundamento da criação artística. Nesse sentido, é interessante pensarmos no teatro. Tendo Dioniso como patrono e utilizando máscaras, ele de certa forma remete o conceito de mímesis para o seu sentido primitivo, de alguém que, tomado por uma instância desconhecida, torna-se outra pessoa. A noção de mímesis percorre o período medieval até que, a partir da Renascença, é retomada com novo vigor pelas poéticas dos séculos XVI, XVII e XVIII, em geral ditas "clássicas" justamente por resgatarem diversos elementos da

*hifvonbiber@yahoo.com.br 
Antiguidade greco-romana de modo explícito e voluntário. Entretanto, não se pode dizer que essa noção se manteve inalterada desde os gregos, tendo o conceito de mímesis passado por um série de modificações.

Em Platão, o conceito de mímesis está inextrincavelmente vinculado aos outros domínios contemplados pelo conjunto de sua filosofia, como a linguagem, a política, a moral e a educação, entre outros. O filósofo parte do pressuposto de que há três realidades possíveis de serem criadas: o arquétipo, que é a realidade verdadeira, denominada idéa em grego, criada por um deus; a cópia do arquétipo, ou phainómenon, criada pelo artífice ou artesão; a cópia da cópia do arquétipo, ou mímema, criada pelo pintor e pelo poeta. ${ }^{1}$ A cópia feita pelo artífice, encontrada na natureza, no mundo humano, é imitação direta da idéa, ou seja, da Verdade (alétheia), ao passo que a cópia feita pelo artista, encontrada na arte, é já imitação da aparência (phántasma). A mímesis, então, é entendida basicamente como imitação da natureza, ou seja, da aparência. ${ }^{2}$ Traduzido como imitatio pelos latinos, esse conceito adquire estatuto ontológico na filosofia platônica, na medida em que se insere na discussão sobre as realidades e sobre a Verdade. Sendo as cópias criadas tanto pelo artífice quanto pelo artista imitações da realidade arquetípica engendrada pelo deus, o filósofo as classifica segundo o grau de distanciamento da Verdade ideal. Nesse sentido, a arte - incluindo aí a poesia encontra-se três graus afastada da realidade verdadeira, já que é cópia de uma cópia. Assim, ela estimula a parte concupiscível da alma (epithymetikón), responsável pelos apetites do instinto e pelo julgamento sem medida, ao invés de promover o desenvolvimento da parte racional (logistikón), que mede, pesa e calcula. ${ }^{3}$ Por isso, constitui-se num elemento nocivo à elevação moral e racional do homem. Uma vez que a filosofia platônica nunca se desprende de uma dimensão moral e pedagógica, a mímesis, para ser boa, ou pelo menos aceitável, deveria debruçar-se sobre um objeto belo e bom, tentando transformá-lo num modelo justo para o ensino dos homens.

Aristóteles parte do mesmo princípio platônico da mímesis como imitação, ${ }^{4}$ mas rejeita a noção de uma mera cópia da natureza, afastada da idéa ou arquétipo, para concebê-la como representação. Isso significa que a natureza não precisa ser recriada exatamente como é, mas como poderia e deveria ser. ${ }^{5} \mathrm{O}$ artista não imita a realidade de forma absolutamente fidedigna, mas nela promove uma melhoria. Tal concepção da mímesis advém de duas principais inovações da filosofia aristotélica em relação à platônica. Primeiro, a de que a natureza ou o mundo dos homens ganha estatuto de realidade independente, não mais sendo concebida como simples imitação de um arquétipo ou de uma idéa. É certo que permanece o pressuposto de que para tudo há uma Causa primeira, ${ }^{6}$ pressuposto que, nas reinterpretações neo-escolásticas da filosofia de Aristóteles promovidas a partir do século XV, será intensificado e tenderá a identificar

\footnotetext{
${ }^{1}$ Cf. PLATÃO. A República, X, 596-598.

${ }^{2}$ Cf. PLATÃO. A República, X, 598.

${ }^{3}$ Cf. PLATÃO. A República, X, 603-606; e LAGE. Teoria e crítica literária na República de Platão, p. 62-66.

${ }^{4}$ Cf. ARISTÓTELES. Poética, $1, \S 2$ (as referências da Poética seguem a edição de Eudoro de Sousa).

${ }^{5}$ Cf. ARISTÓTELES. Poética, $9, \S 50$, que contempla, dentre outros tópicos, a discussão sobre o universal e o particular.

${ }^{6}$ Cf. ARISTÓTELES. Metafísica, $\alpha$, cap. 2.
} 
essa Causa primeira com Deus. Contudo, a realidade empírica participa, enquanto verdade, da substância do mundo. Em segundo lugar, Aristóteles considera que o objeto principal da mímesis, para a poesia, é a práxis humana, ou seja, as ações desempenhadas pelos homens. ${ }^{7}$ Daí decorre que a arte imita não as coisas da natureza, porém suas leis, princípios e proporções. O importante, então, é que essas leis estejam em acordo com a natureza e entre si, formando uma imitação não do verdadeiro, mas do semelhante ao verdadeiro. Esse é, propriamente, o conceito de verossimilhança desenvolvido por Aristóteles, ${ }^{8}$ o qual adquire tamanha importância que ainda nos dias de hoje é utilizado nos estudos literários. Uma obra verossímil pressupõe a representação de uma lógica da natureza, não sua cópia idêntica. Sobre essa questão, Adma Muhana afirma o seguinte:

Se tanto a natureza como o poema são fruto de leis e proporções oriundas da ratio, e se a imitação é um processo de fazer como o da natureza, sem ser o mesmo ou cópia dela, a obra do poeta será uma semelhante à que existe na natureza, independentemente de nela existir ou não. É o que significa verossimilhança, conceito que corresponde à autonomia da obra poética em relação às coisas naturais. ${ }^{9}$

Observemos que a autonomia da obra poética em relação às coisas naturais segue a autonomia das mesmas coisas naturais em relação ao arquétipo, da qual já falamos acima. Assim, para Aristóteles, a mímesis é imitação idealizada e verossímil da natureza, em que a razão das leis e proporções mantém-se como elemento comum entre a realidade imitada e a obra. A verossimilhança torna-se o novo ideal a ser buscado pela poesia, que passa a ser definida por um caráter mais técnico e operacional, em oposição ao caráter ontológico subjacente à noção de Verdade almejada por Platão. Essa mudança é endossada por Plutarco, que no De audiendis poetis abre mão da preocupação ontológica de Platão: "a arte poética não se preocupa, em absoluto, com a verdade" ${ }^{10}$

IMITATIONE

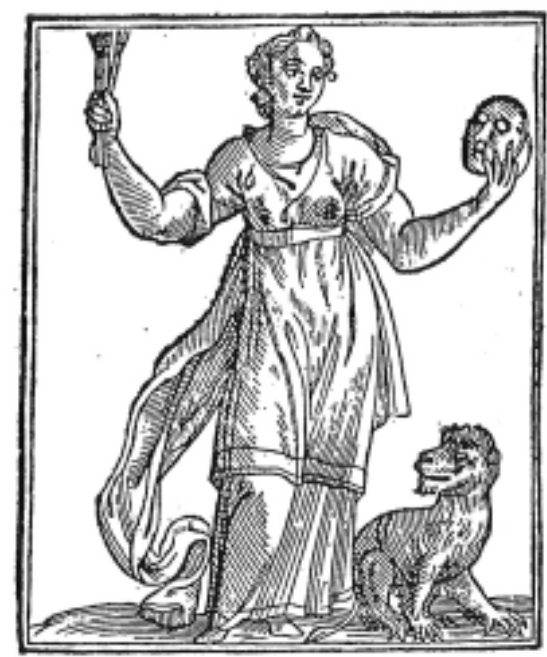

O cruzamento de todas essas noções de mímesis gerou interessantes representações alegóricas do próprio conceito. Uma delas consta na "Nova Iconologia del Cavalier Cesare Ripa Perugino", cuja primeira edição data de 1593. Dentre as diversas alegorias apresentadas na obra, há uma que representa a imitação, a qual reproduzimos a seguir:

Imitatione. RIPA, Cesare. Iconologia.

\footnotetext{
${ }^{7}$ Cf., por exemplo, ARISTÓTELES. Poética, 2, § 7 e 9, § 54.

${ }^{8}$ Cf. ARISTÓTELES. Poética, $9, \S 50$ e 15, § 83-88.

${ }^{9}$ MUHANA. A epopéia em prosa seiscentista: uma definição do gênero, p. 44.

${ }^{10}$ PLUTARCO. De audiendis poetis, 2, $17 \mathrm{~d}$.
} 
Essa figura sintetiza a relação entre arte e natureza contida na noção de mímesis ou de imitatio, segundo a tradução dos latinos. Representada como uma mulher, ela porta, na mão direita, um maço de pincéis, instrumentos da arte e da imitação das cores e das figuras produzidas pela natureza. A mão esquerda segura uma máscara, a qual alude ao teatro e à noção de aparência. A seus pés, há um animal, descrito pelo tratadista como uma scimia (macaco). Este remete à imitação da práxis humana, pois, como afirma Ripa, "la maschera, \& la scimia ci dimostrano l'imitatione dell'attioni humane: questa per essere animale atto per imitare l'huomo coi suoi gesti (...)". ${ }^{11}$

Retomando a questão do desenvolvimento do conceito de mímesis, observamos que a natureza deixa de ser referência absoluta para se tornar apenas um modelo da imitação, cujo procedimento não é uma cópia, mas uma razão, uma ratio. ${ }^{12} \mathrm{Com}$ o tempo, essa noção de modelo começa a se deslocar do âmbito da natureza para o âmbito da própria arte. Adma Muhana elucida esse desenvolvimento lógico na seguinte passagem:

[...] se a poesia é imitação de algo que está na natureza (as ações humanas), e se na natureza em que o homem existe encontra-se também a poesia como efeito de uma ação humana, imitar na poesia a poesia é imitar a natureza. ${ }^{13}$

Assim, desde que alguns escritores foram consagrados pela tradição como exemplos de excelência artística e agrupados num cânone, tornaram-se paradigma para as gerações futuras, as quais passaram a imitar tais modelos. Com isso, a mímesis ganhou também o estatuto de imitação de escritores canônicos, cujos gêneros, linguagem e estilo foram mimetizados por muitos artistas. Essa forma de mímesis estará largamente presente na produção poética a partir da Renascença.

Os primeiros a estabelecer um cânone foram os filólogos alexandrinos, selecionando assim modelos a serem imitados. Posteriormente, essa recomendação já se encontra em escritores da época do Império Romano, sejam de língua latina ou grega, como Cícero, Horácio, Quintiliano, o pseudo-Longino e Luciano de Samósata. ${ }^{14}$ O Tratado da imitação, de Dionísio de Halicarnasso, do século I a.C., é uma das principais obras que teorizam sobre tal concepção. Às vezes ofuscado, nos dias de hoje, pelo brilho de Platão, de Aristóteles e dos latinos, esse tratado é uma excelente fonte para a discussão sobre a imitação de escritores-modelo, atividade denominada de emulação. Esta pode ser definida, conforme o faz o tradutor da versão que consultamos, como um esforço que leva o imitador a igualar, se não a ultrapassar, o próprio modelo, definição corroborada por Quintiliano, segundo o qual "só pela imitação não há crescimento", pois "também serão celebrados aqueles que forem considerados como tendo superado os seus antecessores e

\footnotetext{
${ }^{11}$ RIPA. Iconologia, p. 181-182: "A máscara e o macaco nos mostram a imitação das ações humanas: este por ser animal apto a imitar o homem com seus gestos (...).” (tradução livre de nossa autoria).

${ }^{12}$ cf. MUHANA. A epopéia em prosa seiscentista: uma definição do gênero, p. 40.

${ }^{13}$ MUHANA. A epopéia em prosa seiscentista: uma definição do gênero, p. 41.

${ }^{14}$ Cf., por exemplo: CÍCERO. De oratore, II, §22, 90-92; HORÁCIO. Epistula ad Pisones, 48-53 e 131135; QUINTILIANO. Institutiones oratoriae, X, II (o livro X constitui-se numa espécie de catálogo de modelos, dentro do qual, no capítulo II, Quintiliano discorre sobre a imitação); Pseudo-LONGINO. Do sublime, XIII-XIV; e LUCIANO DE SAMÓSATA. Como se deve escrever a história, § 34.
} 
ensinado os seus sucessores". ${ }^{15}$ Pode-se perceber, então, que no conceito de emulação encontram-se as noções de rivalidade e superação. O sentimento da emulação desperta no artista um desejo de "rivalizar com o que parece haver de melhor em cada um dos antigos" e de "superar as particularidades dessas obras". ${ }^{16}$ Nesse ponto é interessante lembrar que o termo grego traduzido pelos latinos como aemulatio é zélosis, o qual está na origem da palavra portuguesa zelo, mas também da espanhola celo, da francesa jalousie e da italiana gelosia. Enquanto no português a palavra denota cuidado ou proteção, no espanhol, no francês e no italiano ela significa ciúme, inveja. Essa polissemia gerada na evolução do sentido da palavra define bem a relação do escritor com seu modelo: trata-se de uma relação dúbia, de cuidado e ciúme, simultaneamente. Ao mesmo tempo em que o escritor admira seu modelo, guarda-lhe inveja, mas uma inveja positiva. Tal sentimento é esclarecido por Aristóteles, nos capítulos X e XI da Retórica, onde estabelece uma oposição entre a phthónesis, traduzível como inveja, e a zélosis, traduzível como emulação. A primeira se trata da inveja propriamente dita, negativa, que leva alguém a querer destruir seu rival. A segunda se refere ao sentimento de admiração e respeito em relação ao rival, que leva o imitador a querer superá-lo a partir da tékhne e do estilo do próprio modelo. Não é coincidência que, séculos mais tarde, na Renascença francesa, Ronsard se debruce sobre a mesma questão no discurso moral De l'envie (Da inveja). De acordo com o poeta francês, "l'envye est le plus meschant et le plus villain vice de tous (...) L'envye a pour subject de sa malice le plus belles vertus, qu'elle ronge en son cueur, et se ronge elle mesme voullant ronger et menger autruy". ${ }^{17}$ Ao contrário, "l'æmulation est (...) une passion louable, comme ayant son estre d'une bonne volunté d'enssuyvre et d'immiter ce qu'elle void estre le plus excellent (...)" ${ }^{18}$ Assim, tanto o sentimento de inveja quanto o de emulação são despertados pelas belas virtudes, mas é a resposta fornecida por cada um a tal estímulo que os diferencia. Enquanto a inveja gera malícia e corrói o coração daquele que a nutre, a emulação estimula o respeito e a admiração. Portanto, conforme Ronsard, quem desejar se aperfeiçoar no âmbito moral deve sempre buscar a emulação em detrimento da inveja: "Et fault (...) en lieu d'envyeux devenir immitateurs pour tacher à ressembler à celluy dont les vertus et les honneurs nous rendent jaloux et envyeux." ${ }^{19}$ (grifo nosso). Retomando a questão da imitação de uma tékhne e de um estilo, Dionísio de Halicarnasso parece confirmar as ideias de Aristóteles quando diz:

\footnotetext{
${ }^{15}$ QUINTILIANO. Institutiones oratoriae, X, II, 9 e 28 apud DIONÍSIO DE HALICARNASSO. Tratado da imitação, p. 50.

${ }^{16}$ DIONÍSIO DE HALICARNASSO. Tratado da imitação, p. 51-52.

${ }^{17}$ RONSARD. Oeuvres complètes, v. 2, p. 1.040; 1.042-1.043: "A inveja é o mais vil e perverso vício dentre todos (...) A inveja tem como razão de sua malícia as mais belas virtudes, as quais ela corrói em seu coração, e corrói a si mesma desejando corroer e devorar outrem." (tradução livre de nossa autoria). ${ }^{18}$ RONSARD. Oeuvres complètes, v. 2, p. 1.040: "A emulação é (...) uma paixão louvável, tendo em sua essência uma boa disposição de seguir e de imitar o que ela observa ser o mais excelente (...).” (tradução livre de nossa autoria).

${ }^{19}$ RONSARD. Oeuvres complètes, v. 2, p. 1044: "E é necessário (...) em lugar de invejosos nos tornarmos imitadores para nos esforçarmos por assemelhar àquele cujas virtudes e honras nos tornam ciumentos $\mathrm{e}$ invejosos." (tradução livre de nossa autoria).
} 
Com efeito, a imitação não é a utilização dos pensamentos, mas sim o tratamento, como arte, semelhante ao dos antigos. E imita Demóstenes não aquele que diz o mesmo que Demóstenes, mas sim o que diz à maneira de Demóstenes. ${ }^{20}$

No Renascimento, essa mesma relação pode ser identificada não apenas entre escritores antigos e modernos como também entre a língua latina e as línguas vernaculares. O latim ainda é tido como uma língua de excelência, mas já não é a que serve aos escritores. Ao contrário, ele serve de referência para a organização lexical e sintática dos novos idiomas, aos quais imprime prestígio ao ser imitado, concedendo-lhes o estatuto de língua de cultura. Ele torna-se uma língua modelo, análoga a um mestre a quem se busca emular para superar. Não há mais a obrigação de se escrever em latim, mas deve-se escrever à maneira latina, o que trouxe uma renovação na estrutura das línguas vernáculas, sobretudo as românicas. Logo, a categoria da emulação mostra-se bastante produtiva não só para o estudo da literatura como também das línguas da era denominada clássica, entre os séculos XVI e XVIII.

Um outro dado importante presente no Tratado da imitação é a recomendação de se imitarem diversos modelos, e não apenas um. Assim como a mímesis aristotélica promove um aperfeiçoamento da realidade, unindo num universal perfeito o melhor de cada particularidade da natureza, a emulação deve promover um aperfeiçoamento dos modelos, unindo o que cada um tenha de melhor numa forma única, perfeita e bela. Assim se dará a superação desses modelos. Aqui se nota, portanto, a importância dada à leitura e à erudição no Tratado da imitação. Logo, deve-se procurar embelezar o discurso com os recursos provenientes de todos os autores. Esses recursos, se reunidos com a ajuda da arte num único molde de um só corpo discursivo-oratório-artístico, tornam o estilo indubitavelmente melhor.

A categoria da aemulatio, bem como da mímesis em geral, sobreviveu durante a Idade Média latina e chegou com força ao período denominado clássico, entre a Renascença e o Século das Luzes. Alguns dos principais tratados de retórica, poética e estilo dessa época abordam a questão da imitação e da emulação. Na Nova arte de conceitos, do licenciado português Francisco Leitão Ferreira, o autor, numa metáfora engenhosa, compara a atividade do escritor, que deve selecionar os melhores modelos, com a das abelhas, que buscam o pólen das melhores flores:

Assim como a abelha não tece o doce favo do suco de quaisquer flores, mas procura o pasto das mais fragrantes; da mesma sorte, o bom imitador não se deve servir, para sua imitação, de quaisquer figuras, frases e conceitos, mas, lendo e observando os escritos de melhor nota no gênero de obra que fizer, imitará o mais singular, sutil e engenhoso deles, reduzindo a tais regras a sua imitação, que não pareça que trasladou ou traduziu, senão que, competindo com o imitado, o igualou ou excedeu. ${ }^{21}$

Entretanto, o autor muitas vezes parece incorrer no próprio erro que condena, dando-nos a impressão de ter apenas traduzido passagens de outros tratadistas como Emanuele

${ }^{20}$ DIONÍSIO DE HALICARNASSO. Tratado da imitação, p. 50.

${ }^{21}$ FERREIRA. Nova arte de conceitos. Apud TEIXEIRA. A poesia aguda do engenhoso fidalgo Manuel Botelho de Oliveira, p. 58. 
Tesauro e Baltasar Gracián. Comparem-se, por exemplo, os seguintes trechos da Arte dello stile, do cardeal italiano Sforza Pallavicino, e da Nova arte de conceitos, nos quais os autores definem a emulação: ${ }^{22}$

\begin{tabular}{|l|l|}
\hline \multicolumn{1}{|c|}{ PALLAVICINO } & \multicolumn{1}{|c|}{ FERREIRA } \\
$\begin{array}{l}\text { Emulare finalmente é procurar di conseguire con } \\
\text { altri modi nell'animo de' lettori un simile ò } \\
\text { maggior piacere di quello che hanno conseguito } \\
\text { gli Scrittori emulati. }\end{array}$ & $\begin{array}{l}\text { A emulação no imitador, he hu procurar por } \\
\text { differentes modos mover nos animos dos Leytores, } \\
\text { \& ouvintes hum semelhante, ou mayor deleyte, } \\
\text { daquele que moverão os Escritores emulados (...) }\end{array}$ \\
\hline
\end{tabular}

Da mesma forma, o poeta seiscentista português D. Francisco Manuel de Melo trata da imitação em sua obra Hospital das letras, espécie de compêndio de poética e crítica literária. Mostrando-se partidário da ideia de que se deve buscar imitar mais de um modelo, reprova aqueles que seguem apenas um, de modo servil. Numa determinada passagem, Justo Lípsio, um dos personagens que dialogam na obra, afirma:

A imitação, para louvável, quer-se feita com grande destreza, porque o simples séqüito de um só, que vai diante, pertence aos animais, e não aos homens. Quem imita melhor, acrescente, diminua e troque; ou, senão, seja tido por bisonho. ${ }^{23}$

Por essa razão são condenados muitos dos imitadores de Góngora, que o copiam de forma absolutamente inábil e servil:

Todos os que em seus dias e depois deles versificamos temos tomado seu estilo (...) para ver se podíamos escrever, imitando aquela alteza, que juntamente é majestade. Poucos o conseguiram, precipitados, como demônios, do resplandor às trevas; donde disseram muitos mal-intencionados que este engenho viera para maior dano que proveito do mundo, pondo somente os olhos nos desbaratados, e não nos instruídos. ${ }^{24}$

A mesma ideia será postulada, alguns anos depois, por La Fontaine, na Épître à Huet (Epístola a Huet, bispo de Soissons). Embora defendendo a excelência dos antigos no contexto da Querelle des Anciens et des Modernes, da qual falaremos mais à frente, o poeta e fabulista prega uma imitação não subserviente aos modelos:

On me verra toujours pratiquer cet usage;

Mon imitation n'est point un esclavage:

Je ne prends que l'idée, et les tours, et les lois

Que nos maîtres suivaient eux-mêmes autrefois.

Si d'ailleurs quelque endroit plein chez eux d'excellence

Peut entrer dans mes vers sans nulle violence,

\footnotetext{
${ }^{22}$ PALLAVICINO. Arte dello stile; e FERREIRA. Nova arte de conceitos. Apud CASTRO. Retórica e teorização literária em Portugal: do Humanismo ao Neoclassicismo, p. 175.

${ }^{23}$ MELO. Hospital das letras, p. 124. Segundo o editor, bisonho aqui significa inábil.

${ }^{24}$ MELO. Hospital das letras, p. 109.
} 
Je l'y transporte, et veux qu'il n'ait rien d'affecté,

Tâchant de rendre mien cet air d'antiquité. ${ }^{25}$

Recapitulando o nosso percurso, viemos acompanhando, até aqui, o desenvolvimento da noção de imitação, partindo de Platão e chegando até o início do século XVIII. Do cruzamento dos conceitos de mímesis e de zélosis, de imitatio e de aemulatio, surge a ideia de que "imitar a natureza (...) equivale a inventar os casos retóricos, ou seja, escolher as tópicas ou lugares da tradição poética e dispô-los conforme a conveniência dos gêneros literários". ${ }^{26}$ Acreditamos que essa definição dada por Ivan Teixeira resume bem as principais características da imitação, por exemplo, o fato de ela se encontrar na esfera do pseûdos etýmoisin homoîa, ${ }^{27}$ ou da ficção, uma vez que os casos retóricos são inventados e não literalmente copiados da natureza, e também a importância da tradição e dos modelos para essa invenção. Também podemos depreender daí os procedimentos da organização retórica do discurso: a escolha das tópicas caracteriza a fase da inventio, enquanto a sua disposição conforme a conveniência dos gêneros caracteriza o processo da dispositio. Tudo isso será, digamos, temperado com as figuras próprias da elocutio, também retiradas da tradição. Esta adquire tamanho relevo que, como já apontamos acima, multiplicamse os cânones e catálogos de modelos indicativos dos escritores, consagrados pela tradição, que devem ser imitados ou emulados. O próprio Dionísio de Halicarnasso elabora seu catálogo, no livro segundo do Tratado da imitação, distribuindo os modelos selecionados em épicos, líricos, trágicos, comediógrafos, historiadores, filósofos e oradores, e segue tecendo diversos comentários sobre eles.

Os catálogos prosseguem e, a partir do Renascimento, a imitação dos antigos torna-se um dos preceitos fundamentais da criação poética. $O$ poeta português Antônio Ferreira, na Carta XII a Diogo Bernardes, faz um elogio da imitação e da erudição:

Na boa imitação, e uso, que o fero

Engenho abranda, ao inculto dá arte,

No conselho do amigo douto espero.

(...)

Do bom escrever, saber primeiro é fonte.

Enriquece a memória de doutrina

Do que um cante, outro ensine, outro te conte. ${ }^{28}$

\footnotetext{
${ }^{25}$ LA FONTAINE. Oeuvres diverses, p. 645-647: "Serei visto praticar sempre este uso/ minha imitação não é uma escravidão/ tomo apenas a idéia, os contornos e as leis/ os quais nossos mestres, eles mesmos, seguiam outrora./ Se, além disso, alguma passagem de excelência dos antigos/ pode entrar nos meus versos sem nenhuma violência,/ para aí a transporto, e desejo que ela não tenha nada de afetado,/ esforçando-me por tornar meu aquele ar de antigüidade". (tradução livre de nossa autoria).

${ }^{26}$ TEIXEIRA. Mecenato pombalino e poesia neoclássica, p. 251.

${ }^{27} \mathrm{Na}$ Teogonia, de Hesíodo, as Musas afirmam: "ídmen pseúdea pollà légein etýmoisin homoîa", ou seja, "sabemos muitas mentiras dizer semelhantes a fatos". (Cf. HESÍODO. Teogonia: a origem dos deuses, verso 27). Assim, cria-se uma categoria intermediária entre a alétheia - a verdade absoluta - e o pseûdos - o totalmente falso ou mentiroso. O pseûdos etýmoisin homoîa refere-se ao que é falso, mas semelhante à verdade, isto é, ao que é inventado, mas segue as leis da natureza verdadeira, o que também aponta para a categoria do eikós, ou seja, do verossímil.

${ }^{28}$ Citação retirada de SPINA. Introdução à poética clássica, p. 11.
} 
Joachim du Bellay, na Deffense et illustration de la langue françoyse, igualmente, recomenda a imitação dos antigos gregos e latinos:

Se compose doncques celuy qui voudra enrichir sa langue, à l'imitation des meilleurs auteurs grecs et latins; et à toutes leurs plus grandes vertus, comme à un certain but, dirige la pointe de son stile; car il n'y a point de doute, que la plus grand'part de l'artifice ne soit contenue en l'imitation. $(. . .)^{29}$

Mas também postula a imitação de alguns escritores mais recentes, como os humanistas italianos: "Pour le sonnet doncques tu as Petrarque et quelques modernes Italiens. Chante moy (...) marines à l'exemple de Sennazar gentil homme Néapolitain." 30

As ideias de imitação de mais de um modelo e de superação desses modelos anteriores podem estar na base de uma progressiva imitação de escritores contemporâneos a partir de fins do século XVI. Os antigos deixam gradativamente de ser autoridade única para ceder lugar aos modernos que porventura tenham atingido um mesmo nível de perfeição. Obviamente essas mudanças não foram aceitas por todos, gerando conflitos que levaram, por exemplo, à Querelle des anciens et des modernes, na França do século XVII. Trata-se de uma polêmica surgida na Academia Francesa, que opunha duas correntes, a saber: os Antigos, liderados por Boileau, que concebiam a criação artística como imitação dos gregos e latinos, os quais teriam atingido o mais alto patamar da perfeição formal, segundo seus defensores; e os Modernos, encabeçados por Charles Perrault, partidários de uma renovação da criação literária, com base na ideia de que os clássicos gregos e romanos não eram insuperáveis e de que o século de Luís XIV poderia produzir artistas de altíssima qualidade. A disputa teve início em 1687, quando Perrault apresenta à Academia o poema Le siècle de Louis le Grand, no qual promove o elogio do Rei Sol e relega a Antiguidade clássica a segundo plano enquanto modelo de criação artística, como se pode observar nos provocativos versos iniciais:

La belle antiquité fut toujours vénérable;

Mais je ne crus jamais qu'elle fût adorable.

Je vois les anciens, sans plier les genoux;

Ils sont grands, il est vrai, mais hommes comme nous;

Et l'on peut comparer, sans craindre d'être injuste,

Le siècle de Louis au beau siècle d'Auguste. ${ }^{31}$

\footnotetext{
${ }^{29}$ DU BELLAY. La défense et illustration de la langue française, p. 58: "Harmonize-se então aquele que deseja enriquecer sua língua com a imitação dos melhores autores gregos e latinos; e a todas as suas maiores virtudes, como a um objetivo certeiro, dirija a ponta de seu estilo; pois não há dúvida de que a melhor parte do artifício esteja contida na imitação (...).” (tradução livre de nossa autoria).

${ }^{30}$ DU BELLAY. La défense et illustration de la langue française, p. 87: "Para o soneto, então, tens Petrarca e alguns modernos italianos. Que eu cante (...) marinas ao exemplo de Sannazzaro, fidalgo napolitano." (tradução livre de nossa autoria).

${ }^{31}$ PERRAULT. Oeuvres choisies, p. 290: "A bela antigüidade foi sempre venerável; / Mas não creio que ela foi adorável. / Eu miro os antigos sem dobrar os joelhos, / Eles são grandes, é verdade, mas homens como nós; / E podemos comparar, sem temer ser injustos, / O século de Luís ao belo século de Augusto." (tradução livre de nossa autoria).
} 
Tal fato provocou um protesto imediato da parte de Boileau. No ano seguinte, Perrault prossegue com a polêmica, ao publicar quatro volumes de um Parallèle des anciens et des modernes.

Alguns estudiosos tendem a apontar, como origem da Querelle francesa, uma primeira querela italiana entre antigos e modernos, da época da Renascença. De qualquer forma, é fato que esses debates já se encontravam na ordem do dia antes de 1687 e em outras nações europeias. D. Francisco Manuel de Melo, por exemplo, morto em 1666, nos dá um exemplo disso no âmbito português. O autor, embora reconhecendo o valor dos escritores antigos consagrados pela tradição, admite a imitação dos modernos e não considera impossível que estes sejam melhores:

(...) se conferirmos os estilos dos poetas antigos e modernos, estes farão muita vantagem àqueles, porque a argentaria e lentijuela que hoje se gasta é sem dúvida mais brilhante e agradável que a melancólica frase dos antigos. Se hoje ressuscitassem ao mundo aqueles famosos Símacos, Orfeus e Clenandros, e ateimassem em trajar o entendimento pelas medidas do tempo entanguido, a gente fugeria deles. Não digo, por isto, que deixemos de venerar e reconhecer mil brasas ardentes, dissimuladas por entre aquelas cinzas frias, como vemos em o ouro, que, nascendo de um parto com a Terra, não apodrece em suas entranhas, antes por benefício da idade se sublima em valor e pureza. Nego, contudo, o que afirmam outros, que só em aqueles primeiros séculos fosse liberal a natureza em produzir altos juízos (...) Honrai, Senhor, a antiguidade, para que da posteridade sejais honrado; mas não honremos uma por desonrar outra. ${ }^{32}$

Aliás, retomando a questão da doutrina e do saber, recomendados por Antônio Ferreira, D. Francisco afirma que os modernos são melhores doutrinadores em se tratando de casos específicos, por estarem mais próximos dos costumes de seus leitores contemporâneos:

Aqueles autores que universalmente ensinam não importa que sejam antigos, antes porventura são melhores, porque nas primeiras idades do mundo, dado que as ciências não estivessem tão descobertas nos mestres, estava mais pura a aptidão nos discípulos; porém aqueles que especialmente nos ensinam sobre pontos determinados é bem que sejam modernos, ou porque esses resolvem já as dúvidas opostas da malícia, ou porque, sendo mais vizinhos a nós, se conformam com os nossos usos e praticam os remédios da sua corrupção. ${ }^{33}$

De qualquer forma, é fato que vários artistas passaram a emular seus contemporâneos. O caso de Góngora, discutido por D. Francisco, é um ótimo exemplo. Assim, os escritores dos séculos XVI e XVII passam a realizar um volumoso número de glosas dos autores admirados. Esse ato aponta fundamentalmente para a permanência do paradigma da mímesis enquanto a característica mais essencial do poiein, isto é, do fazer poético dessa época.

Assim, podemos apontar duas acepções para a palavra glosa. A primeira, de sentido mais estrito, refere-se ao procedimento de composição poética em que um autor toma um poema alheio e desenvolve seus versos, inserindo-os, com ou sem modificações, no corpo de seu próprio poema. Hans Janner, um dos poucos críticos que se dedicaram ao estudo minucioso da glosa, elucida algumas de suas características. Em primeiro lugar, "toda glosa comprende dos partes: una poesía temática elegida o impuesta que se llama

\footnotetext{
${ }^{32}$ MELO. Hospital das letras, p. 101-102.

${ }^{33}$ MELO. Hospital das letras, p. 231.
} 
generalmente texto, y estrofas (la glosa propiamente dicha) en las que se interpretan los distintos versos de texto". ${ }^{34}$ Por outro lado,

(...) es condición de la glosa propiamente dicha el que cada uno o cada dos de los versos temáticos se glosen en sus estrofas respectivamente. Los versos del texto han de insertarse de tal manera - generalmente al final de la estrofa de la glosa - que queden incorporados orgánicamente a ésta por el sentido y por la rima. ${ }^{35}$

Uma definição muito semelhante nos dá um tratado de poética do século XVII, a Arte Poética, e da Pintura, e Simetria com alguns Princípios da Perspectiva, de Filipe Nunes, publicada em 1615. Diz o autor:

As Grosas constam de texto, e grosa. O texto é o mote, ou seja, de ua ou duas regras, ou de qualquer outro modo que se oferecer. E pode ser de sonetos, de outavas, de liras, ou a alvedrio do Poeta, metendo o verso que grosa no fim do soneto, outava, ou lira. E note-se que quando grosarem vão sempre seguindo algua matéria, e não ua para um verso, e outra para o outro, que é defeito grande. ${ }^{36}$

Por essa razão, não se pode definir uma forma fixa para a glosa, pois sua realização depende da métrica e das rimas do poema escolhido para ser glosado. "De ahí procede (...) la peculiaridad de que no se pueda fijar su estructura exterior por un solo esquema", ${ }^{37}$ segundo Janner. Entretanto, o estudioso identifica uma forma consagrada pela tradição devido ao seu uso mais frequente:

El problema métrico de la glosa, pues, viene dado principalmente por las formas de las estrofas y los sistemas de rimas a aquéllas vinculados, sin determinarse por un sistema fijo, como el soneto o el terceto. Durante la evolución de la glosa en el siglo XVI, sin embargo, se impuso una forma especial que yo he denominado "normal" y que es el resultado de [un] desarrollo histórico (...) Intégrase este tipo "normal" de la glosa por un texto de cuatro versos octosílabos ${ }^{38}$ y la misma glosa por cuatro décimas octosílabas cuyos décimos versos son los cuatro versos temáticos que entran en ellas rimando y formando sentido (... $)^{39}$

De fato, essa forma tem largo alcance na tradição poética quinhentista, e um ótimo exemplo de seu emprego pode ser encontrado em Camões, nas glosas ao seguinte mote:

Campos bem-aventurados,

Tornai-vos agora tristes,

Que os dias em que me vistes

Alegre, já são passados. ${ }^{40}$

${ }^{34}$ JANNER. La glosa en el siglo de oro, p. 72.

${ }^{35}$ JANNER. La glosa en el siglo de oro, p. 72.

${ }^{36}$ NUNES. Arte poética, p. 100.

${ }^{37}$ JANNER. La glosa en el siglo de oro, p. 72.

${ }^{38}$ A classificação dos versos aqui utilizada segue o sistema de escanção conhecido como contagem espanhola, diverso da contagem francesa, utilizada nos manuais de versificação da língua portuguesa desde o século XIX. Para maiores informações sobre esse tópico, cf. ALI. Versificação portuguesa; AZEVEDO FILHO. Estruturalismo e crítica de poesia; AZEVEDO FILHO. A técnica do verso em português; e, ainda, CHOCIAY. Teoria do verso, 1974.

${ }^{39}$ JANNER. La glosa en el siglo de oro, p. 72.

${ }^{40}$ CAMÕES. Obras, p. 743. 
Outros exemplos de glosas stricto sensu, do século XVII, podem ser encontrados nos principais cancioneiros da poesia seiscentista portuguesa, a Fênix Renascida e o Postilhão de Apolo, cujas páginas estão cheias de glosas de diversos escritores considerados modelos, entre eles Góngora, Quevedo e sobretudo Camões. Além disso, a título de curiosidade, e para demonstrar que o conceito de glosa era extremamente difundido nos séculos XVI e XVII, lembremos aqui que ele também se aplica a outros domínios artísticos fora das letras. Na música, por exemplo, há um interessante Tratado de glosas sobre cláusulas y otros géneros de puntos en la música de violones, de autoria do espanhol Diego Ortiz, publicado em Roma em 1553. Ali podemos identificar a mesma noção de glosa, compartilhada com o domínio poético. Sobre temas alheios, muitas vezes anônimos e tomados da tradição, denominados clausulas, o compositor ensina a desenvolver melodias e improvisos guardando suas principais características rítmicas, melódicas e harmônicas.

Da seguinte afirmação de Janner retiramos a segunda acepção de glosa, de caráter mais geral e abrangente: "la glosa no es solamente una forma métrica, un molde, sino que procede de una idea, de un propósito que es el de comentar poesías de pluma ajena". ${ }^{41}$ De certo modo tal acepção retoma e conclui nosso percurso, pois a concebemos como reescrita, releitura ou interpretação de um outro texto, de um tema, de um estilo, de um gênero desenvolvido por outrem. Nessa acepção a glosa se confunde com a própria imitação. Podemos entendê-la como a retomada das tópicas e das convenções retóricas de um escritor consagrado pela tradição como modelo, seja ele "antigo" ou "moderno". Em suma, o ato de glosar - e, em seu sentido lato, entendamos também mimetizar, imitar, emular, canonizar etc. - define bem a vasta literatura chamada de clássica compreendida aproximadamente entre o século XVI e o XVIII, ou entre a Renascença e o Iluminismo, período também denominado de Era clássica, por diversos historiadores da literatura.

\section{RESUMÉE}

Les poétiques des siècles $\mathrm{XVI}^{\mathrm{e}}, \mathrm{XVII}^{\mathrm{e}}$ et $\mathrm{XVIII}{ }^{\mathrm{e}}$, appelées "classiques" pour reprendre des éléments de l'Antiquité gréco-latine, se règlent largement par la notion de mímesis pour l'élaboration de ses présuppositions et préceptes. Donc cet article cherche à étudier l'évolution et l'amplification du concept de mímesis au long des siècles et réfléchir sur sa permanence dans celles poétiques-là, en distinguant ses nouveautés et spécificités, développées par la littérature de l'époque.

\section{MotS-CLÉS}

Mímesis, glose, Littérature classique

\footnotetext{
${ }^{41}$ JANNER. La glosa en el siglo de oro, p. 73.
} 


\section{REFERÊNCIAS}

ALI, Said. Versificação portuguesa. Rio de Janeiro: Ed. Gernasa, 1970.

ARES MONTES, Jose. Góngora y la poesia portuguesa del siglo XVII. Madrid: Gredos, 1956. $496 \mathrm{p}$.

ARISTOTE. Art réthorique et art poétique. Traduction, introduction et notes par Jean Voilquin et Jean Capelle. Paris: Garnier, 1944. XIII + 572 p.

ARISTÓTELES. Arte retórica e arte poética. Trad. do francês por Antônio Pinto de Carvalho. Rio de Janeiro: Ediouro, [196-]. 358 p.

ARISTÓTELES. Metafísica. Edição trilíngue por Valentín Garcia Yebra. 2. ed. revisada. Madrid: Gredos, 1982. LIII + 830 p.

ARISTÓTELES. Poética. Tradução, prefácio, introdução, comentário e apêndices de Eudoro de Sousa. Lisboa: Imprensa Nacional/Casa da Moeda, 1986. 316 p.

ARISTÓTELES. HORÁCIO. LONGINO. A poética clássica. Introdução de Roberto de Oliveira Brandão. Trad. Jaime Bruna. 7. ed. São Paulo: Cultrix, 1997. 114 p.

AUERBACH, Erich. Mímesis: a representação da realidade na literatura ocidental. 4. ed. Trad. G. B. Spencer. São Paulo: Perspectiva, 2002. (Estudos, 2). 507 p.

AZEVEDO FILHO, Leogendário Amarante de. Estruturalismo e crítica de poesia. Rio de Janeiro: Ed. Gernasa, 1970.

AZEVEDO FILHO, Leogendário Amarante de. A técnica do verso em português. Rio de Janeiro: Acadêmica, 1970.

BOMPAIRE, Jacques. Lucien écrivain: imitation et création. Paris: Les Belles Lettres: Nino Aragno, 2000. 794 p.

CAMÕES, Luís de. Obras. Porto: Lello \& Irmão, [1970?]. X + 1459 p.

CARVAlHO, Maria do Socorro Fernandes de. Poesia de agudeza em Portugal. 2004. Tese (Doutorado em Letras) - Instituto de Estudos da Linguagem, Universidade Estadual de Campinas, Campinas. $269 \mathrm{f}$.

CASTRO, Aníbal Pinto de. Retórica e teorização literária em Portugal: do Humanismo ao Neoclassicismo. Coimbra: Centro de Estudos Românicos da Faculdade de Letras da Universidade de Coimbra, 1973. 754 p.

CICERON. De l'orateur. Texte établi et traduit par Edmond Courbaud. Paris: Les Belles Lettres, 1957-66. v. 2. 196 p.

CHOCIAY, Rogério. Teoria do verso. São Paulo: McGraw-Hill do Brasil, 1974.

DIONÍSIO DE HALICARNASSO. Tratado da imitação. Tradução, introdução e notas por Raul Miguel Rosado Fernandes. Lisboa: INIC/Centro de Estudos Clássicos da Universidade de Lisboa, 1986. [? p.]

DU BELLAY, Joachim. La défense et illustration de la langue française. Suivie du projet de l'oeuvre intitulée De la précellence du langage françois par Henri ESTIENNE. Nouvelle édition revue et annotée par Louis Humbert. Paris: Garnier, 1930. 589 p.

HESÍODO. Teogonia: a origem dos deuses. Trad. Jaa Torrano. 3. ed. São Paulo: Iluminuras, 1995. $166 \mathrm{p}$. 
HORACE. Texte latin. Introduction par E. Sommer. Paris: Hachette, 1881. 422 p.

JANNER, Hans. La glosa en el siglo de oro. Madrid: Ediciones Nueva Época, 1946. 95 p.

LA FONTAINE, Jean de. Oeuvres diverses. Texte établi et annoté par Pierre Clarac. Paris: Gallimard, 1942. v. 2. (Bibliothèque de la Pléiade, 62). XLV + 1094 p.

LAGE, Celina Figueiredo. Teoria e crítica literária na República de Platão. 107 f. 2000. Dissertação (Mestrado) - Faculdade de Letras, Universidade Federal de Minas Gerais, Belo Horizonte, 2000.

LUCIANO DE SAMÓSATA. Como se deve escrever a história. Tradução e ensaio de Jacyntho Lins Brandão. Belo Horizonte: Tessitura, 2009. 280 p.

MELO, D. Francisco Manuel de. Hospital das letras. In: . Apólogos dialogais.

Lisboa: Sá da Costa, 1959. v. 2.

MUHANA, Adma. A epopéia em prosa seiscentista: uma definição de gênero. São Paulo: Ed. UNESP, 1997. 344 p.

NUNES, Filipe. Arte poética. In: GOMES, Paulo J. Pedrosa S. Filipe Nunes - Arte poética: um tratado maneirista de métrica. Estudo introdutório, estabelecimento do texto e notas. [19-]. Dissertação (Mestrado em Letras) - Faculdade de Letras, Universidade de Coimbra, Coimbra.

ORTIZ, Diego. Tratado de glosas sobre cláusulas y otros géneros de puntos en la música de violones. Übertragen von Max Schneider. Halle: Bärenreitaer-Augsgabe, 1936. XXXVII + 136 p. PERRAULT, Charles. Oeuvres choisies. Paris: Dondey-Dupré, 1826. Fac-similé. CIV + 347 p. PLATÃO. A República. Introdução, tradução e notas de M. H. da Rocha Pereira. 9. ed. Lisboa: Fundação Calouste Gulbenkian, 2001. LX + 513 p.

PLUTARQUE. Oeuvres morales. Paris: Les Belles Lettres, 1972. t. I, v. 1, $1^{\text {ère }}$ partie. CCCXXIV + $173 \mathrm{p}$.

QUINTILIEN. Institution oratoire. Texte revu et traduit par Henri Bornecque. Paris: Garnier, 1954. v. IV (livres X-XII). 408 p.

RIPA, Cesare. Iconologia. Edizione pratica a cura di Piero Buscaroli. Prefazione di Mario Praz. Milano: TEA, 1992. XVII + 600 p.

RONSARD, Pierre de. Oeuvres complètes. Paris: Gallimard, 1950. 2v. (Bibliothèque de la Pléiade, 19 et 20).

SPINA, Segismundo. Introdução à poética clássica. São Paulo: FTD, 1967. 151 p.

TEIXEIRA, Ivan. A poesia aguda do engenhoso fidalgo Manuel Botelho de Oliveira. In: OLIVEIRA, Manuel Botelho de. Música do Parnaso. Cotia: Ateliê Editorial, 2005. Edição fac-similar. p. 7-96.

TEIXEIRA, Ivan. Mecenato pombalino e poesia neoclássica. São Paulo: Edusp, 1999. 620 p. 